\title{
Bricolagem e processo de invenção literária: o signo na sua relutância icônico/verbal
}

Bricolage and process of literary invention: the sign in its iconic / verbal reluctance

\author{
Aguinaldo José Gonçalves \\ PUC-Goiás/ UNESP \\ agnus.fenix@gmail.com
}

\begin{abstract}
RESUMO: O texto discute a relevância da abordagem semiótico-discursiva para os estudos do discurso literário e do discurso plástico. Para isso algumas obras são analisadas, tais como: "O elefante" de Carlos Drummond e Andrade, e "Uns inhos engenheiros" de João Guimarães Rosa. O aspecto mais destacado do estudo consiste na visão teórica de bricolagem como recurso fundamental para a composição do trabalho de arte. Desenvolvemos essa teoria tendo como ponto de investigação a obra Figures de Gérard Genette. Outros teóricos foram utilizados e um dos mais importantes foi Jean-Claude Coquet para as abordagens da semiótica literária.
\end{abstract}

Palavras-chave: Bricolagem. Poética. Metáfora. Semiótica. Signo.

\begin{abstract}
The paper discusses the relevance of semiotic- discursive approach to the study of literary discourse and artistic discourse. For that some works are analyzed, such as: "O elefante" of Carlos Drummond Andrade, and "Uns inhos engenheiros" de João Guimarães Rosa. The most prominent aspect of the study is the theoretical view of bricolage as a fundamental resource for the composition of the artwork. We developed this theory having as research central in mage the work of Gérard Genette, Figures. Other theorists were used and one of the most important was Jean-Claude Coquet for the approaches about literary semiotics.
\end{abstract}

Keywords: Bricolage. Poetics. Metaphor. Semiotics. Sign.

O signo e as questões que o envolvem conduzem às implicações intersemióticas das mais variadas vertentes críticas. $\mathrm{O}$ que deve ser

Revista Texto Poético | ISSN: 1808-5385 | Vol. 18 (10 sem-2015) - p. 143 
considerado relevante é a competência semiótica de ampliação dos limites do signo em manifestações poéticas e estéticas determinantes para a projeção do trabalho inventivo. Ao dizer isso, temos de levar em conta os vários sistemas ou os sistemas plurais de articulação da linguagem em suas nuanças expressivas.

De uma fotografia analógica para uma pintura acadêmica e de uma pintura acadêmica para uma pintura não figurativa de Paul Klee (1979) ou Wassily Kandinsky (1981) temos uma gradação de expansividade do signo icônico que transforma, consideravelmente, a potencialidade do signo. No caso do poema ou do discurso poético de intensividade relevante, o mesmo procedimento ocorre. Entretanto, dada a natureza do signo linguístico possuidor de uma necessária relação entre significante e significado ou entre expressão e conteúdo, as dimensões de expansividade do signo passam por processos de plasmação da forma para a constituição do signo poético. Este pode atingir gamas de higienização dos resíduos semânticos do mundo em detrimento de sua limpeza na passagem da língua um para a dois, dentro do processo de realização que se coloca entre a instância um (composição) e a instância três (modulação).

Ao atingir uma intensividade elevada, no processo de depuração do signo verbal, o discurso poético aponta para o que poderia ser chamado de signo complexo. Nessa instância de formulação, tal processo possibilita uma elevação e enlevação do signo verbal a uma condição de signo icônico na condição diagramática. O discurso poético de excelência faz "ver", não no sentido referencial e analógico do termo, mas no diagramático e abstrato. Para que isso seja possível, o signo não pode resistir à construção de um objeto poético, mas os estilhaços de signo devem

Revista Texto Poético | ISSN: 1808-5385 | Vol. 18 (10 sem-2015) - p. 144 
conduzir a esse objeto. A isso, a essa construção semissimbólica do objeto, podemos denominar, valendo-me de uma expressão de Gérard Genette, de processo de bricolagem.

Passemos, então, a discutir um aspecto determinante no processo de invenção literária e reinvenção do signo. Referimo-nos ao procedimento da bricolagem, de extrema necessidade para que o mundo seja reinventado via linguagem e de resultados efetivos para a elaboração das grandes obras. Gérard Genette (1972) em Figures afirma que um dos escolhos da análise temática consiste na dificuldade que ela encontra, muitas vezes, em distinguir a parte que cabe à singularidade irredutível de uma individualidade criadora, da que pertence mais amplamente ao gosto, à sensibilidade, à ideologia de uma época ou, mais abertamente ainda, às convenções e às tradições permanentes de um gênero ou de uma forma literária.

Um dos momentos iluminados do pensamento crítico se deve a Gérard Genette e se situa no capítulo "Estruturalismo e Crítica Literária". Trata-se dos procedimentos associativos a respeito da relação entre o pensamento mítico de Claude Lévi-Strauss e o processo de bricolagem intelectual. O que nos moverá nesta reflexão é a transposição das relações entre criação e crítica (engenharia e bricolagem) para o movimento reverso do procedimento de criação e crítica. Indo adiante nessas relações residuais entre "sucatas da experiência" e criação poética, na segunda parte do mesmo capítulo, Genette faz evoluir seu pensamento para questões fundamentais do verso e de sua função no interior do poema.

\section{O ELEFANTE (fragmento)}

Fabrico um elefante

de meus poucos recursos. 
Um tanto de madeira tirado a velhos móveis talvez lhe dê apoio. E o encho de algodão, de paina, de doçura. A cola vai fixar suas orelhas pensas. A tromba se enovela, é a parte mais feliz de sua arquitetura. Mas há também as presas, dessa matéria pura que não sei figurar.

Tão alva essa riqueza a espojar-se nos circos sem perda ou corrupção. E há por fim os olhos, onde se deposita a parte do elefante mais fluida e permanente, alheia a toda fraude.

Eis o meu pobre elefante pronto para sair à procura de amigos num mundo enfastiado que já não crê em bichos e duvida das coisas. Ei-lo, massa imponente e frágil, que se abana e move lentamente a pele costurada onde há flores de pano e nuvens, alusões a um mundo mais poético onde o amor reagrupa as formas naturais. (DRUMMOND, 1974). 
Nesse alegórico texto de A Rosa do Povo o poema é representado pelo "elefante", objeto construído pelo processo de bricolagem. Por uma questão de economia e de pertinência para o assunto tratado. As três estrofes alegorizam a relação entre o poeta $\mathrm{e}$ o meio expressivo de que se vale para construí-lo e torná-lo pronto para entrar em comunicação com o mundo. Trata-se de um poema belíssimo em que o caráter artesanal do processo se manifesta. $\mathrm{O}$ processo de bricolagem é descrito com perfeição e chega a ser didático: "fabrico um elefante / de meus poucos recursos. / Um tanto de madeira / tirado a velhos móveis". Construir um objeto novo valendo-se do que se tem às mãos. Esse é o princípio. E valendo-se de elementos antitéticos (madeira $\mathrm{X}$ algodão), este objeto consistente e ao mesmo tempo frágil; esse objeto que revela seu avesso e, se quiser, sua inconsistência $\mathrm{X}$ durabilidade, como sói ocorrer com o poema.

Valendo-nos de uma pequena digressão da linha em que trilhávamos o caminho principal da moderna poesia brasileira, vamos dar uma entrada numa estrada secundária que não prejudicará nosso percurso. A propósito, este texto não tem como escopo parar em certas ilhas ou em certos redutos, mas refletir de modo geral sobre os pontos a que nos propusemos discutir. Essa questão da bricolagem, tão cara ao processo de construção da obra literária, é exemplar no exercício inventivo de João Guimarães Rosa. Essas ideias foram publicadas anteriormente num pequeno ensaio para a Revista USP por ocasião dos 30 anos de morte do escritor mineiro a convite daquela Revista que muito me honrou.

As razões creio prescindirem de uma explicitação, sobretudo para o público brasileiro que tanto se orgulha do universo literário criado pelo escritor mineiro. A missão crítica deve ter como meta,

Revista Texto Poético | ISSN: 1808-5385 | Vol. 18 (10 sem-2015) - p. 147 
sempre que possível, a tentativa de dar certa voz ao objeto com que lida, para que esse objeto possa transitar com maior intensidade entre as pessoas que nele buscam melhor compreensão, primeiro dos sinais que o formam, depois daqueles que constituem o seu próprio universo interior. A literatura consiste nessa intrincada composição de hieróglifos de cuja articulação emanam sentidos essenciais que tendem a mobilizar nossos juízos indo ao encontro do que temos de mais preservado. Entretanto, esse discurso não tem como objetivo desenvolver nenhuma grande descoberta. Ele pretende apenas homenagear um estilo que conseguiu ir mais além de uma obsessão individual e atingir com sua intensidade a visão de todos nós, leitores de Guimarães Rosa. Assim, coloco-me nesse discurso mais como leitor e menos como crítico, nele transmitindo minha simples visão. Nada espero dele a não ser a sua confessional posição. Se com isso conseguir deitar alguma voz a esse estilo, muito bem. Se não, terá valido como o registro de meu posicionamento frente a ele.

Torna-se completamente impossível, para um aficcionado nas artes e na literatura, refletir sobre o processo composicional de João Guimarães Rosa sem tentar encontrar a chave do mistério do inaudível que ele mantém resguardada em cada gesto de linguagem. Todas as teorias, todos os modelos fornecidos pelas ciências da linguagem parecem se tornar procedimentos racionais que permanecem numa antessala do espaço que ele fabrica e que consegue nos demover do que se poderia denominar simulacro do real e nos obriga a conviver, mesmo que em forma de impressão, com a dimensão mítica, primordial que parece, por caminhos os mais tortuosos, dar-nos a consciência de uma dimensão mística.

Nesse sentido, tentar esboçar um discurso que consiga tangenciar o universo engendrado por esse escritor, significa refletir 
sobre poesia, ou melhor, a eficácia da linguagem em estado de poesia, independente da forma escolhida para que se manifeste. Digo isso porque esse foi o legado que nos deixou o autor de Grande Sertão: Veredas. Sua obra, toda a sua obra, consiste numa permanente remissão para a esfera prismática da linguagem poética, construída sem se valer da forma convencional do verso, mas determinada por um ritmo crespo, composto de pequenos garranchos, ou de ramos secos, que se enviesam e se emaranham em cada tentativa de fluência, ficando ali, em cada ponto de seus contornos, matizados pelo próximo nó entre ramagens que apenas são possíveis se se tem a linha como base.

A "frase" de Guimarães Rosa esconde em si o verso e a prosa, não sendo assim nenhum dos dois para se transformar na ferrugem da retórica e, ao mesmo tempo, na temperatura máxima de um procedimento alquímico sobre metais de várias naturezas. Por isso, falar de seu estilo ou de sua "frase fundamental" é falar da frase mínima da poesia, no sentido mais estrito do termo, que resvala alguma coisa que antecede os princípios fundamentais da língua, dadas a intensidade e complexidade com que se foi além. Mas também é falar da frase mínima da prosa, uma espécie de núcleo actancial, como se fosse o gesto primordial que impulsiona o sujeito à ação pendular, por meio do qual passa a existente. Entre uma coisa e outra mantém-se o quase, condição entreposta e pendular que atuam como eternidade mítica de uma realidade vertical do ser humano. Essa "frase especial" se constrói por uma elevação muito alta dos componentes linguísticos motivados em cada elemento mínimo por procedimentos estilísticos que promovem, desde o primeiro balbucio sonoro, o que prefiro denominar de onomatopeia metafórica, em que se compõem gestos icônicos por excelência. 
A palavra, quase gesto, fica sempre engastada em forma de imagem e se apresenta sempre como nó que apenas se desmancha se entra em sintonia com os universos recônditos de quem a recebe ou que com ela se inteire. Se compreendemos a poesia lírica como linguagem em alto grau de eficácia, como sendo uma forma de arte especial da palavra, podemos compreender o texto de Guimarães Rosa como lirismo em alta tensão, com seu aspecto próprio, qual seja, uma engenhosidade mimética da própria forma horizontal e contínua da linguagem da prosa; uma fabricação tendo como matéria-prima o signo verbal e suas potencialidades constitutivas capazes de gerar um objeto estranho e fascinante que resguarda da sua função primeira, apenas o simulacro.

Contudo, averiguando bem, o melhor caminho para se conseguir aproximar desse fascinante objeto feito de palavras, mas que consegue transcender a elas por meio de procedimentos singulares é buscar, na própria conceituação, seus dois atributos básicos, qual seja, sua contenção e sua contensão e esses dois atributos enformam o discurso de G. Rosa em quase todas as suas manifestações. Como diz Paul Valéry (1983), no sentido vago do termo, todo mundo é capaz de poesia, aqui compreendido como a captação de estados de sensibilidade para certas impressões, emoções de origem exterior ou interior ao sujeito. Entretanto, ainda diz o grande poeta e ensaísta francês, entre a emoção e sua expressão existe uma grande distância, ou até mesmo um abismo.

A poesia consiste no engendramento de um ritmo que se enforma como se delineasse estados de sensibilidade e não exprimisse um estado particular. Para isso entendemos que haja necessidade, no mínimo, de uma habilidade do gênio criador de pelo menos observar com profundidade o mundo ou os pequenos mundos

Revista Texto Poético | ISSN: 1808-5385 | Vol. 18 (10 sem-2015) - p. 150 
que trazem em seu espaço os átomos que podem ser desagregados ao ponto de gerarem outras relações com outros espaços. São eles que nos instigam à apreensão de novos estados ou daqueles que dormitavam em nosso espaço interior. Esses estados no universo de Guimarães Rosa nos conduzem a dimensões que não conseguimos deslindar, que ficam ali dentro de nós querendo evocar universos perdidos, mundos buscados pela atmosfera que povoa nosso sonho ou dimensões de nosso inconsciente, mesclando-se aos nossos sentimentos mais profundos, deixando-nos, assim, à mercê de uma condição, sem fala, uma vez que não consigamos descrever. E tudo isso se dá por meio de um ritmo.

Esse ritmo se realiza plasmando uma forma que se mantém no interstício da semantização e da transracionalidade e, tantas vezes, é no transracional que finalmente o compreendemos. Mas essa compreensão é dada pelo ininteligível, pelo silêncio que os garranchos sonoros, matizados por fragmentos sêmicos nos invadem. Do mesmo modo que um poema lírico de alta tensão imagética necessita de um trabalho paciente e, muitas vezes, árduo, em que o artista consegue passar do estado imediato àquela expressão mais estudada e fundada sobre o conhecimento de nossos semelhantes e de sua maneira de reagir, o texto de Guimarães Rosa revela esse paciente trabalho e o eleva a um grau de manifestação realizado pela melhor poesia lírica. Melhor, portanto, é a não distinção, sobretudo hierárquica, dos gêneros, mas compreender tudo isso como a produção do texto artístico desse grande escritor, que é capaz de produzir, em estado extraordinário, determinados efeitos expressivos da linguagem que jamais seriam produzidos em estado ordinário.

Revista Texto Poético | ISSN: 1808-5385 | Vol. 18 (10 sem-2015) - p. 151 
Para Valéry (1983), dentre esses efeitos produzidos pela poesia existe um que é particularmente significativo e que pode ser chamado de efusão rítmica. Assim, ser poeta consiste na propriedade de se sentir produtor de ritmo. O ritmo pode, em muitos casos, representar uma espécie de categoria harmônica que precede a própria concretização verbal do poema. Mesmo essa concretização pode se iniciar por meio de rudimentos sonoros, alguns signos, uma sintaxe fragmentariamente emergente, tudo isso se articulando de modo a concluir a totalidade poética. Pode-se ainda falar com base em Valéry de certo dispositivo rítmico que atua como elemento revelador que vai, pouco a pouco, buscando, ou encontrando, ou fazendo emergir determinados elementos verbais capazes de confluir para significações nem sempre esperadas, mas que munidas ou conformadas ao ritmo comporão o conjunto da composição que de maneira alguma pode perder a natureza rítmica inicial.

Tenho particularmente a impressão de que o desenho de um poema, sua conformação orgânica representa sempre o desenho ou o delineio de um estado arquetípico do humano em algum recorte combinatório de suas vicissitudes espirituais. E seria essa conformidade que denominamos rítmica, pois é como se ela denunciasse os movimentos mais internos, mais abstratos, que nem sempre corresponderiam às mesmas pegadas do sujeito individual, alterando a trajetória de um para outro indivíduo num ou noutro tempo de sua existência ou de sua disponibilidade sensível (penso "sensível" no sentido kantiano). Exatamente por isso que se fala da circularidade do poema, de seus componentes de repetição conformadores da imagem.

A imagem do poema ou o poema como imagem concentra todos os filamentos necessários para que se opere a viagem do interlocutor.

Revista Texto Poético | ISSN: 1808-5385 | Vol. 18 (10 sem-2015) - p. 152 
É a porta por onde se entra para o início de uma navegação mítica que de maneira alguma pode ser substituída por outra. A outra tem trajetória própria que conduzirá ao mesmo outro ponto sem que se possa precisar a rota. Essa natureza singular do poema tem sua origem em fundamentos de sua constituição nem sempre bem definida pelos tratados de poética. O ponto de partida para que possa adentrar a esfera do poema ou de qualquer objeto de investigação crítica reside na busca de compreensão de sua natureza, na busca de compreensão do referido objeto. Para Jean-Claude Coquet (1984) as relações que ocorrem no interior do objeto poético não correspondem a um dado imediato. Evidentemente, esse pensamento de Coquet, com o qual compartilho, vem apontar para a necessidade de se perscrutar o objeto literário de modo a perceber e compreender alguns passos gerados pelo texto que possam nos conduzir às tais relações de sentido. O conhecimento do analista vai favorecer que se apreendam as correspondências de camadas geradoras do objeto.

As tentativas da semiótica francesa ou da retórica geral contemporânea em determinar uma gramática específica da poesia pode favorecer o reconhecimento de procedimentos genéricos que constituem os elementos macroestruturais dessa forma de linguagem, mas cremos ser inviável uma gramática que possa dar conta dos elementos microestruturais, pois são eles que constituem o que se poderia denominar de fenômeno construtivo responsável pelo desenho singular a que aludimos. É certo que a poesia consiste numa arte verbal e que sua base estrutural é linguística. Entretanto, cremos que sua realização se dá numa outra ordem de coisas, numa esfera da subtração linguística e não na sua conformidade. Para Louis Hjelmslev (1977), um signo é uma entidade gerada pela conexão entre uma expressão e um conteúdo. Essa definição tem por

Revista Texto Poético | ISSN: 1808-5385 | Vol. 18 (10 sem-2015) - p. 153 
base a funcionalidade do signo. Dentro dessa ideia, diz o linguista dinamarquês que, na verdade, deve-se falar da função do signo colocada entre duas entidades, uma expressão e um conteúdo. Há solidariedade entre a função de signo e seus dois funtivos, a expressão e o conteúdo. Jamais haverá uma função de signo sem a presença simultânea desses dois funtivos. Uma expressão e seu conteúdo, ou um conteúdo e sua expressão, jamais aparecerão juntos sem que esteja presente entre eles a função de signo. Expressão e conteúdo se pressupõem necessariamente.

Uma expressão só é expressão em virtude de que é expressão para um conteúdo, e um conteúdo só é conteúdo em virtude de que é conteúdo para uma expressão [substância do conteúdo $=0$ pensamento; substância da expressão $=$ cadeia de sons]. A substância depende da forma até o ponto de viver, exclusivamente, a causa dela e não pode em nenhum sentido dizer-se que tenha existência independente. Sentido, para Hjelmslev, é a denominação dada ao princípio comum a todas as línguas, apesar de suas diferenças. Não compreendo a diferença a ser estabelecida, para ele, entre substância do conteúdo (pensamento) e sentido (pensamento mesmo). Em cada uma das línguas consideradas terá de se analisar de modo diferente, fato esse que só pode ser interpretado como indicativo de que o sentido foi ordenado, articulado, conformado de modo distinto nas línguas distintas. Sentido informe se conforma em línguas distintas. O sentido continua sendo, em cada caso, a substância de uma nova forma, e não tem existência possível se não for sendo substância de uma forma ou de outra.

Parece-nos, agora, ter ficado clara a relação entre sentido e substância, isto é, não significa a mesma coisa, mas uma espécie de correspondência semântica. Reconhecemos, portanto, no conteúdo

Revista Texto Poético | ISSN: 1808-5385 | Vol. 18 (10 sem-2015) - p. 154 
linguístico, no seu processo uma forma específica, a forma do conteúdo que é independente do sentido e mantém uma relação arbitrária com o mesmo, e que lhe dá forma em uma substância do conteúdo. Tudo isso ocorre em correspondência com a da expressão. O signo é, pois - por paradoxal que pareça -, signo de substância do conteúdo e da expressão. Neste sentido, é que se pode dizer que o signo é signo de algo. A partir dessas ricas considerações de Hjelmslev, inicia-se um movimento dentro de nosso juízo a respeito da conotação, sobretudo na linguagem poética. Entretanto, o que nos põe a pena na mão não é a questão da linguagem poética por ela mesma, mas pelo que esta forma de expressão é capaz de ditar, não se incomodando com as categorizações ou as tentativas de divisões entre gêneros.

Os gêneros são delineamentos do homem nas suas mais dinâmicas formas de sentir e de tentar ser. Por determinações que fogem a nossas capacidades operacionais de busca, a expressão artística se realiza dentro do que poderíamos denominar de visão, bem mais que as técnicas que fazem materializar um objeto dito literário. Essa profusão de gêneros talvez seja o maior legado, deixado pelo grande escritor. Nesses trinta anos de sua morte, assiste-se a uma tendência cada vez maior da própria literatura e, consequentemente, das várias vertentes críticas em se tentar compreender mais que as diferenças e as semelhanças entre a chamada prosa literária e a poesia.

É claro que essa preocupação é antiga, mas também que, ao menos no Brasil, ela se acentuou muito, depois que os textos de Guimarães vieram à luz. $\mathrm{O}$ seu processo composicional aponta para si mesmo, recobrando o que lhe é de direito: determinação do espaço da linguagem. É nesse espaço, na fricção de suas figuras e de sua 
modulação que se instauram os sentidos, utilizado aqui, estritamente, no sentido empreendido por Hjelmslev e que levou tradutores de várias línguas a tentar apreendê-lo, por meio das formas de expressão que se conectam às de conteúdo de seus idiomas.

Aludirei, neste pequeno texto-homenagem, a uma pequena invenção de Rosa que, ao menos dentro de nossos limites de apreensão de seus recursos, consideramos o mais bem realizado. Afirmamos isso com certa disponibilidade de espírito sem o qual recairíamos nos grandes textos, nos extensos textos de Guimarães Rosa, todos eles sobejamente estudados, sob o ponto de vista da macroestrutura. Um dia, um professor universitário, ao falar de sua tese de doutorado, disse-me que lidava com grandes estruturas literárias em detrimento de "tijolinhos" literários que, segundo ele, eram minhas preocupações.

Pois bem, ao realizar essa simples homenagem ao grande artista, a mais um tijolinho e mais ainda àquele que considero a sua preciosidade maior, à pérola, para lembrar uma expressão de Roger Shattuck (1984) referindo-se a certos procedimentos de Marcel Proust (1970), que, uma vez apreendido, apreendeu-se à porção mágica do estilo desse escritor. Sou munido, portanto, nessas palavras, por um dos menores textos da obra maior, denominado "Uns Inhos Engenheiros". Este título, o menor do mundo, munido de finíssimas agulhas, ínfimas, com linhas também finas, que parecem precisar de estereoscópio para que se possa tecer o alto relevo das imagens, plasmadas num baixo relevo que em si é um tecido, o ninho, esse artefato, extensão do humano, outra forma de origem, renascente, útero do existente, querendo o retorno, no eixo entre o fora e dentro, o ninho: 
Onde eu estava ali era um quieto. O ameno âmbito, lugar entre-as-guerras e invasto territorinho, fundo de chácara. Várias árvores. A manhã se-a-si bela: alvoradas aves. O ar andava, terso, fresco. O céu-uma blusa. Uma árvore disse quantas flores, outra respondeu dois pássaros. Esses, limpos. Tão lindos, meigos, quê? Sozinhos adeuses. E eram o amor em sua forma aérea. Juntos voaram, às alamedas frutíferas, voam com uniões e discrepâncias. Indo que mais iam, voltavam. O mundo é todo encantado. Instante estive lá, por um evo, atento apenas ao auspício (ROSA, 1984).

É assim, na cobertura de que todos precisamos e que, aos nossos olhos, já é ditada pela natureza, no conforto e consolo que envolve nossos ombros e nosso coração que o texto se inicia para construir a teia do amor aéreo, figurativizada por dois pássaros que voam com uniões e discrepâncias nesse triste encanto de mundo em que o céu é uma blusa. Estrutura mínima: dois pássaros construindo seu ninho. Estrutura temática média: dois pássaros metaforizando a construção, a materialização do amor. Estrutura complexa: a construção da teia abstrata transcendente e ao mesmo tempo primordial, retida no som e na sintaxe, na morfossintaxe, no léxico, nas figuras ou semisímbolos, nos resíduos sonoros que amalgamados uns aos outros se instauram aquém ou além dos fonemas, aquém ou além da dupla articulação humana, e só assim consegue resgatar o primado do ser, o ser em si do sentimento que mais faz do homem ser homem, bem distante da racionalidade, nessa força e nessa forma instintiva, primeira e única de ser do amor.

Como em círculos concêntricos as gamas de sentidos vão-se inter-relacionando, numa gradação profusa dos ingredientes a partir dos quais se podem produzir os sentidos latentes ou fazê-los emergir da própria tessitura. Guimarães Rosa cria um objeto de arte valendo-

Revista Texto Poético | ISSN: 1808-5385 | Vol. 18 (10 sem-2015) - p. 157 
se do máximo de contenção da linguagem com o mínimo de matériaprima. Parece preencher um recipiente muito pequeno com praticamente toda a gama de recursos expressivos da palavra, elevada ao grau máximo de seus limites. Escolhe como matériaprima dois assanhaços no ato de construir seu ninho e, a partir dela, constrói o universo do amor, essa complexidade sintetizadora de todas as vicissitudes humanas.

Não é ao acaso que seleciona alguns tipos de pássaros que conjugados formam o discurso salpicado, passaredo, plenos de suas características próprias na composição do canto e do movimento delicado e intenso de seus passamentos, de suas manifestações mais puras: os assanhaços ou sanhaços que consistem [do tupi sa'i wa'su] designação de várias aves passeriformes, da família dos traupídeos, de coloração verde ou azul-acinzentada, e asas com enfeites variados. Alimentam-se, sobretudo, de frutas, sendo assíduos frequentadores de pomares e hortas, onde costumam causar danos de monta, o sabiá, o guaxe,

o tico-tico, a guarricha, as rolas: No entre mil, porém, este par valeria diferente, vê-se de outra espécie - de rara oscilabilidade e silfidez. Quê? Qual? Sei, num certo sonho, um deles já acudiu por "o apavoradinho”, ave Maria! e há quem lhes dê o apodo de Mariquinha Tece-Seda. São os que sim sós. Podem se imiscuir com o silêncio. $O$ ao ato. A alma arbórea. A graça sem pausas. Amavio. São mais que existe o sol, mais a mim, de outrures. Aqui estamos dentro da amizade (ROSA, 1984).

É assim, depois de criar o quadro especial dos pássaros por meio de um chilreio metafórico em que a natureza começa a ter voz, dentro dessa atmosfera composicional, que o narrador elege o par de 
rolas para adentrar a esfera da tarefa séria: o trabalho de construção do ninho. Evidentemente, na dimensão de consciência de João Guimarães Rosa, a fabricação do ninho consiste na metáfora discursiva de alto grau de elevação que se reporta ao próprio ato de construção do texto. Esse elemento de constituição tensiva entre a função poética e a função metalinguística da obra de arte verbal possui a maestria de produzir sentidos, de fornecer a possibilidade de nos tirar do primeiro nível de compreensão para nos remeter aos vários patamares de ambiguidade promovidos pelo texto. A materialização dos signos, sua potencialidade de iconização promove o atrativo maior do universo de palavras por ele articulado.

No caso desse texto, que nos vale como exemplo genuíno do que representa essa forma de linguagem, num determinado ponto que consideraríamos de excelência em todos os ingredientes concorrem para a fabricação do ninho artístico, assim se expressa o narrador:

O ninho - que erguem -; e nexil, pléxil, dificil. Já de segredo o começaram: com um bicadinho de barro, a lama mais doce, a mais terna. De barro, dos lados, à vária vez, ajuntam outros arrebiques. À muita fábrica, que se forma de ticos, estilhas, gravetos, em curtas proporções; e argueiros, crinas, cabelos, fibrilas de musgos, e hábeis ciscos, discernidas lãs, painas - por estofo. Com o travar, urdir, feltrar, enlaçar, entear, empastar, de sua simples saliva canora, e unir, com argúcia e gume, com - um atilho de amor, suas todas artes. Após, ao fim, na afofagem, forrá-lo com a própria única e algodoída penugem - do peito, a que é mais quente do coração. O ninho - que querem - é entre asas e altura. Como o pássaro voa trans abismos. A mais, num esperanceio: o grácil, o sutil, o pênsil (ROSA, 1984). 
Eis o fenômeno da criação. O movimento perfeito do processo e o modo de sua produção. Suas especificações e seus segredos. Todos revelados e ao mesmo tempo resguardados no corpo do signo transmudado, decifrado e elevado à condição de sopro como se tudo tivesse sido estabelecido desde o princípio. Existe logo na primeira linha o indício fundamental. Ao separar por travessões a expressão "que erguem" Guimarães Rosa repete um recurso dos mais preciosos nesse sentido de indício ou de indicação para o próprio processo de fabricação. Destaca a expressão por sinais de pontuação que denunciam o seu contrário. É certo, sob o ponto de vista do assunto empreendido, que o texto descreveria a construção de um ninho, referência plausível que determina a coerência referencial do texto. Entretanto, ao assinalar a expressão reitera o caráter da ambiguidade e nos apresenta o seu contrário. O "ninho textual" é que vai emergindo, que vai sendo erguido aos nossos olhos, tendo se iniciado desde o primeiro rumor da língua, posta em condição de imagem poética. E é dessa imagem (o próprio texto) resultante do engenho do artista que se pode falar com Júlia Kristeva de significância ou do texto como provedor de sentidos.

\section{Referências}

ANDRADE, Carlos Drummond de. A rosa do povo. Rio de Janeiro: Aguilar, 1974.

GENETTE, Gérard. Figures. Trad. Ivonne Floripes Mantoanelli. São Paulo: Perspectiva, 1972.

GONÇALVES, Aguinaldo José. O Legado de João Guimarães Rosa. Dossiê 30 Anos sem Guimarães Rosa, São Paulo, Revistausp, n. 36, p. 6-17, dez. 1997/fev. 1998.

Revista Texto Poético | ISSN: 1808-5385 | Vol. 18 (10 sem-2015) - p. 160 
HJELMSLEV, Louis. Prolegómenos a una teoría del linguaje. Trad. José Luiz Díaz de Liaño. 2. ed. Madri: Gregos, 1977.

JAKOBSON, Roman. O dominante. In: LIMA, Luiz Costa (org.). Teoria da literatura em suas fontes. Trad. Jorge Wanderley. 2. ed. Rio de Janeiro: Francisco Alves, 1983.

. Linguística e comunicação. São Paulo: Cultrix, 1974.

KANDINSKY, Wassily V. De lo espiritual en el arte. Trad. Elisabeth Palma. México: Premiá, 1981.

KLEE, Paul. Teoria del arte moderno. Trad. Hugo Acevedo. Buenos Aires: Caldén, 1979.

KRISTEVA, Julia. Introdução à semanálise. Trad. Lúcia Helena França Ferraz. São Paulo: Perspectiva, 1974.

PROUST, Marcel. Em busca do tempo perdido. Trad. Lúcia Miguel Pereira. Porto Alegre: Globo, 1970.

ROSA, João Guimarães. Ave, palavra. Rio de Janeiro: José Olympio, 1984 VALÉRY, Paul. Discurso sobre a estética. In: LIMA, Luiz Costa (org.) Teoria da literatura em suas fontes. Trad. Eduardo Viveiros de Castro. 2. ed. Rio de Janeiro: Francisco Alves, 1983.

SHATTUCK, Roger. The innocent eye: on modern literature and art. Nova York: Farrar Strauss Giroux, 1984. 